\title{
Early cognitive profiles of emergent readers: A longitudinal study
}

\author{
Nicola Brunswick ${ }^{\mathrm{a},{ }^{*},}$, G. Neil Martin ${ }^{\mathrm{a}}$, Georgina Rippon ${ }^{\mathrm{b}}$
}

${ }^{a}$ Department of Psychology, School of Health \& Social Sciences, Middlesex University, The Burroughs, Hendon, London, NW4 4BT, UK.

${ }^{\text {b }}$ Department of Psychology, School of Life and Health Sciences, Aston University, Birmingham, B4 7ET, UK.

* Corresponding author. Department of Psychology, School of Health \& Social Sciences, Middlesex University, The Burroughs, Hendon, London, NW4 4BT, UK. Tel.: +44 0208411 5343; fax: +4402084114259.

E-mail address: n.brunswick@mdx.ac.uk (N. Brunswick)

Published as: Brunswick, N., Martin, G.N. \& Rippon, G. (2012). Early cognitive profiles of emergent readers: a longitudinal investigation. Journal of Experimental Child Psychology, 111, 268-285. DOI: 10.1016/j.jecp.2011.08.001 


\begin{abstract}
This longitudinal study examined the contribution of phonological awareness, phonological memory, and visuospatial ability to reading development in 142 English-speaking children from the start of kindergarten to the middle of grade two. Partial cross-lagged analyses revealed significant relationships between early performance on block design and matching letter-like forms tasks and later reading ability. Rhyme awareness correlated with later reading ability in the earliest stages but onset awareness did not emerge as important until after the children had started reading. Digit span correlated significantly with future reading ability at every stage. These findings indicate that while phonological awareness, phonological memory, and visuospatial ability are all necessary for emergent reading, their relative importance varies across the first two years of reading development.
\end{abstract}

Key words: longitudinal study, partial cross-lagged correlations, reading development, phonological memory, phonological awareness, visual ability 


\section{Introduction}

While reading is rapid and automatic in skilled readers, in beginning readers it only emerges as a result of the complex and effortful interaction between perceptual and linguistic processes (Schatschneider, Fletcher, Francis, Carlson, \& Foorman, 2004). These processes rely on the child's grasp of fundamental skills-visual perceptual skills, awareness of the sounds of the spoken language, short-term memory skills-which develop in the preschool years before the commencement of reading instruction. While much is known about the interactions between these skills and reading ability in early readers, skilled readers, and impaired readers, less is known about the relationships between these skills in pre-readers and emergent readers. The aim of this study was to shed new light on these relationships from the start of kindergarten to grade two.

\section{Cognitive Predictors of Reading Development}

It is generally accepted that while phonological skills are important for the development of reading, children often identify words initially on the basis of their shape rather than their constituent sounds (Ellis \& Large, 1988; Frith, 1985). The ability to recognize whole words depends upon the child's ability to process, and distinguish between, visual forms yet relatively little is known about the development of visual skills (the perception of visual forms and patterns) in pre-readers, and of the role that these play in early reading development. Studies have explored children's early knowledge of alphabetic print (Lonigan, Burgess, \& Anthony, 2000; Parrila, Kirby, \& McQuarrie, 2004; Storch \& Whitehurst, 2002), or their familiarity with environmental print (Goodman, 1986; Lonigan et al., 2000), and these have reported that preschool/grade one knowledge of alphabetic letters and word forms predicts subsequent reading development. Other researchers have asked preschool children to copy or match simple alphanumeric symbols (Badian, 2001), to reproduce visual patterns from memory (Vellutino, Tunmer, Jaccard, \& Chen, 2007), or to remember relationships between visual forms (Huang \& Hanley, 1997). However, these tasks still involve the recognition or matching of alphanumeric symbols, or they involve a substantial memory component; either of these factors will confound the interpretation of the results. One aim of the 
current study was to investigate preliterate children's ability to process non-alphanumeric stimuli to determine the contribution that visual perceptual skills make to early reading development, and to see how long this effect endures once reading commences.

Phonological awareness is the ability to identify, distinguish between, and manipulate sounds within spoken language, and its importance to reading is widely acknowledged such that children who are better able to identify and manipulate individual sounds are more successful than their peers when learning to read (Carroll, Snowling, Hulme, \& Stevenson, 2003; Lonigan et al., 2000; Parrila et al., 2004). However, the concept of phonological awareness is broad, and different aspects of phonological awareness emerge at different points in a child's development. While awareness of larger phonological units, such as the syllable and onset-rime, develop independently of reading instruction in three- to five-year-old children (Badian, 2001; Bradley \& Bryant, 1983; Gipstein, Brady, \& Fowler, 2000), awareness of smaller units of sound, such as the phoneme, usually only develop later as a result of reading development (Cardoso-Martins \& Pennington, 2004; de Jong \& van de Leij, 1999; although see Ziegler \& Goswami, 2006 for discussion of the development of phonemic awareness across languages). Given the high degree of inter-correlation between different phonological skills, it is necessary to tease apart the influence of each one to explain the reported relationships between different phonological skills and reading.

As few longitudinal studies have administered measures of phonological processing to preschool children, relatively little is known about the early development of phonological awareness or the utility of such measures as predictors of emergent reading ability (Carroll et al., 2003; Parrila et al., 2004). Some have reported that preschool measures of phonological processing correlate with reading ability through the first school year (Badian, 1994; de Jong and van der Leij, 1999; Lervåg, Bråten \& Hulme, 2009; Torgesen, Wagner, \& Rashotte, 1994) and up to four years later (Cardoso-Martins \& Pennington, 2004; Kirby, Parrila, \& Pfeiffer, 2003; Parrila et al., 2004). However, this relationship has been questioned, with studies indicating that preschool phonological awareness is a poor and inconsistent predictor of later reading ability once autoregressive effects 
(effects that may be explained by the presence of a skill at a previous time, or by reciprocal relationships between measures at a previous time) have been controlled for (Badian, 2000; Duncan \& Seymour, 2000; Lervåg et al., 2009; Muter \& Snowling, 1998; Wimmer, Landerl \& Schneider, 1994).

Alongside phonological awareness, phonological memory-the temporary storage of soundbased information, also often referred to as verbal short-term memory-has been identified as a key component of phonological processing that is necessary for reading development (Alloway et al., 2005; Gathercole, Service, Hitch, Adams \& Martin, 1999; Wagner \& Torgesen, 1987).

Phonological memory predicts vocabulary acquisition by providing a temporary phonological representation of unfamiliar words while the individual forms an enduring representation in longterm memory (de Jong \& Olson, 2004; Gathercole \& Baddeley, 1989). It also contributes to the acquisition of letter knowledge (de Jong \& Olson, 2004), it supports the identification of words during the application of grapheme-phoneme correspondence rules, and it facilitates text comprehension by enabling children to remember words they have already read (Baddeley, 1986; Gathercole \& Baddeley, 1989). It correlates with current reading ability (Alloway et al., 2005; Hulme, 1988; Parrila et al., 2004) and with future reading ability (Gathercole, Tiffany, Briscoe, Thorn, \& ALSPAC Team, 2005; Parrila et al., 2004; Torgesen et al., 1994), and significant differences have been found between good and poor readers in terms of their memory for letters and digits (Ackerman \& Dykman, 1993; McCrory, Frith, Brunswick, Price, 2000), words (Brunswick, McCrory, Price, Frith, \& Frith, 1999; McCrory et al., 2000; Muter \& Snowling, 1998) and sentences (Hansen \& Bowey, 1994; Miles, Thierry, Roberts, \& Schiffeldrin, 2006).

Wagner and Torgesen (1987) placed particular emphasis on the distinction between phonological awareness and phonological recoding in working memory which they identified as having separable predictive relationships with reading. This idea has received support from other studies which have shown that while phonological memory and phonological awareness both reflect phonological ability, they exert independent influence over reading development (e.g., 
Gathercole, Willis, Emslie, \& Badeley, 1991; Hansen \& Bowey, 1994; Windfuhr \& Snowling, 2001). However, others have reported that once the variance caused by phonological awareness is controlled for, the remaining variance predicted by phonological memory is minimal, and in some cases non-significant (e.g., Gottardo, Stanovich, \& Siegel, 1996; Lervåg et al., 2009; McDougall, Hulme, Ellis, \& Monk, 1994; Rohl \& Pratt, 1995).

Two important questions, in terms of our understanding of the relationships between phonological ability and reading, are: how much contribution do phonological awareness and phonological memory make to variance in reading skill at different stages of normal reading development? And, are reading skills a cause or a consequence of phonological memory span and phonological awareness? Many studies which have attempted to answer these questions have taken no objective measure of reading ability at the first time of testing (this is discussed further below), thus although it would appear that phonological memory exerts an influence over later reading development, these studies permit no investigation of the possible reciprocal influence of reading ability on phonological memory. An aim of the current study was to investigate the influence of phonological memory in the pre-reader over their subsequent reading development.

\section{Methods of Assessment of Children's Reading Development}

While longitudinal studies provide valuable insights into the relationship between cognitive ability and reading development in children (Carroll et al., 2003; Chapman \& Tunmer, 1997; Phillips, Norris, Osmond, \& Maynard, 2002), some have tested children only over a relatively short period of time-e.g., a single year (Carroll et al., 2003; Huang \& Hanley, 1997) - or they have attempted to determine developmental pathways in cognitive abilities by comparing groups of children cross-sectionally (Lonigan et al., 2000; Roman, Kirby, Parilla, Wade-Woolley, \& Deacon, 2009; Stahl \& Murray, 1994; Vandervelden \& Siegel, 1995). One problem with this type of study is that each group may have numerous factors - differences in IQ, parental input, or teaching methods - which impact on reading ability via an undefined third element, thereby confounding the 
data. The only valid way to study developmental changes associated with reading is to test the same group of participants over an extended period.

The timing of testing sessions is critical. It is not uncommon in longitudinal studies to measure a cognitive skill at an initial stage of testing, either in kindergarten or at the start of school, and to relate this measure to reading ability at a later stage, generally towards the end of the first school year (e.g., Lonigan et al., 2000; Mann \& Liberman, 1984). Such designs fail to take into account causal influences of reading ability at stage one over reading ability at stage two, possibly leading to an over-statement of the influence of the skill under investigation (Byrne et al., 2002). If the intention is to determine predictors of reading development, it is necessary that the first stage of testing occurs as early as possible, at least before the start of formal education, as Lonigan (2007) notes, “... the acquisition of literacy [is] a developmental continuum with its origins early in the life of a child, rather than an all-or-nothing phenomenon that begins when children start school" (p. 18). Longitudinal studies in which testing commences in or after grade one (e.g., Abbott, Berninger, \& Fayol, 2010; Huang \& Hanley, 1997; Onatsu-Arvilommi \& Nurmi, 2000; Sprenger-Charolles, Siegel, Béchennec, \& Serniclaes, 2003; Vellutino et al., 2007) miss this crucial period of development and make it difficult to disentangle cause and effect between the variables.

Reciprocal causality between cognitive skills must also be considered (Bradley \& Bryant, 1985; Stanovich, Cunningham, \& Cramer, 1984). As kindergarten education in Britain and the USA generally involves an introduction to the rudimentary skills necessary for reading (Adams, 1990), finding that a cognitive skill in preschool children predicts reading ability in the first school year may reveal nothing more than that early reading ability predicts later reading ability. To examine the emerging relationship between reading and other cognitive skills it is necessary to measure all variables of interest at every stage, and to control for the pre-existing effects of these variables at all stages.

\section{The Current Study}


The ability to read does not exist in isolation from the development of the child's cognitive repertoire, and different skills appear to be important at different stages of reading development. However, as Vellutino et al. (2007) note: “...the relative contribution made by phonological and visual skills as well as by higher level language skills to reading development have not been extensively evaluated" (p. 5). This study, therefore, investigated the relationship between reading development, visuospatial ability, phonological awareness, and phonological memory in 142 children learning to read English in the UK. It conformed to Wagner and Torgesen's (1987) suggestion that longitudinal studies should comprise a large group of children tested on at least three occasions: (i) before the children could read, (ii) at a stage of early reading acquisition, and (iii) when reading skills had been acquired, so the sample was followed from the start of kindergarten through to the second year at school. All children were identified as non-readers at the beginning of the study.

The specific questions addressed in this study were: Which variables measured in kindergarten best predicted the emergence and development of reading skills across the first two years of compulsory schooling? And how stable is the relationship between each individual variable and reading ability through the early years of reading development once autoregressive effects have been controlled for? We predicted that performance on the visuospatial tests would be important only in the earliest stages of reading development, while performance on the tests of phonological awareness and phonological memory would have more far-reaching influence over reading development across the course of the study.

\section{Method}

\section{Participants}

The initial sample comprised 72 girls and 70 boys $(M=45.4$ months, $S D=4.6)$ at two staterun kindergartens in a large market town in England. Written consent for participation was provided by the kindergartens and by the children's parents or guardians. English was the only language spoken at home by 140 of the families of participating children. Of the two children whose families 
did not have English as the sole language spoken within the home, one had English as the primary language, the other had English as an additional language. However, analysis at each stage showed that these two children's results fell within one standard deviation of the sample mean.

Testing commenced three months into the children's first year in kindergarten (Stage 1). Stage 2 occurred at the end of this year $(M=50.6$ months, $S D=4.9)$. By Stage 3, six months later, the children had begun full-time education at elementary school. Most children moved to the schools to which the kindergartens were attached but a few moved to other schools and became unavailable for testing. The sample at this stage comprised 56 boys and 52 girls $(M=57.5$ months, $S D=4.4)$. Stage 4 occurred at the end of grade one $(M=62.8$ months, $S D=4.8)$ and one girl was lost from the sample. Stage 5 occurred towards the end of the first term of grade two. By this time, three more children had moved away leaving 53 boys and 51 girls $(M=68.9$ months, $S D=3.9)$. Another boy moved from the area prior to the final testing session of this stage so his reading ability data are not available. No statistically significant differences were found on any stage 1 variable between children who remained in the study until Stage 5 ( $73 \%$ of the initial sample) and those who were lost from the study over the intervening stages.

\section{Procedure}

At each stage testing was undertaken in two sessions, separated by two days, to reduce fatigue and the demands on the children's attention. Children were tested in a quiet room away from the classroom, and the order of test presentation was randomized within each session.

Randomization was achieved by writing the names of the tests on slips of paper which were placed face down on the table and shuffled at the start of each session. Tests were administered to each child in the order in which the slips of paper were selected and turned over.

The block design, matching letter-like forms, recall of digits, and word reading tests were standardized measures taken from the British Ability Scales; these are widely used in the UK and have proven validity and reliability (see Elliott, 1983). The Bradley and Bryant (1983) oddity task 
was selected as one of the most frequently used measures of rhyme and alliteration awareness in the UK (see Macmillan, 2002; Muter, Hulme, Snowling, \& Stevenson, 2004).

\section{Measures}

Block design. According to the manual this test provides a measure of "spatial visualization" although it is also widely used to assess non-verbal intelligence (see Bowyer-Crane, Snowling, Duff, Fieldsend, Carroll, Miles, Götz, \& Hulme, 2008; Kokis, Macpherson, Toplak, \& Stanovich, 2002; Nampijja et al., 2010). It requires children to arrange painted wooden blocks so the designs on top of the blocks match those printed in the test booklet (Elliott, Murray, \& Pearson, 1983) so attention to visual detail is crucial for the completion of this task. According to the manual, the Hoyt reliability coefficient for this test is .80 .

Matching letter-like forms. This task requires children to identify a target letter-like form from amongst a selection of six alternatives. It provides a measure of "the development of visual discrimination skills in young children which in turn is relevant to their acquisition of reading and writing skills" (Elliott et al., 1983). The Hoyt reliability coefficient for this test is .77.

Recall of digits. This measure of "immediate auditory recall" (Elliott et al., 1983) requires participants to remember and report spoken sequences of numbers of gradually increasing length, e.g., 54, 242, 8495. Span is calculated as the maximum list length that the child correctly reported. The Hoyt reliability coefficient for this test, reported in the test manual, is .83 .

Word reading. Reading ability was assessed by having the children read aloud words of increasing difficulty (from the, at, one to character, mosquito, chaos). The test continues until the child has either read all of the words correctly or failed on five successive words. Performance on this test, which provides "a measure of context-free word recognition" (Hatcher \& Hulme, 1999), correlates highly with "other measures of reading achievement, such as... reading comprehension or... accuracy obtained from the presentation of prose passages" (Elliott et al., 1983). The Hoyt reliability coefficient for this test is .98 . 
Phonological oddity task. This task, a measure of phonological awareness, requires participants to identify the "odd word out" from four. Three of the monosyllabic words sound similar while one differs in its first sound (e.g., rot, rod, rock, box), its middle sound (e.g., mop, hop, tap, lop) or its last sound (e.g., hat, mat, fan, cat). These tasks assess sensitivity to "onset similarity" (first-sound-different) and "rhyme similarity" (middle-sound- and last-sound-different: Wimmer et al., 1994). In each condition two practice trials with corrective feedback are followed by eight test trials. The estimated reliability coefficients for these tasks were all at or above .70 from Stage 3 onwards (at each stage reliability was slightly greater for the tests of rhyme similarity than for onset similarity). Reliability coefficients in the initial two stages failed to reach this criterion.

\section{Results}

Descriptive data for each measure at each stage are shown in Table 1. It is clear that there was a tendency for performance on each measure to improve across successive testing stages. Initial analyses explored these changes using one-way repeated-measures analyses of variance with testing stage as the within-subjects factor. Block design score was entered as a covariate in the analysis of the phonological oddity task, phonological memory task, matching letter-like forms task and reading task data to control for the influence of general non-verbal cognitive ability (see BowyerCrane et al, 2008; Kokis et al, 2002; Nampijja et al., 2010). Additionally, phonological memory score was entered as a covariate in the analysis of the phonological oddity task data to control for the influence of memory on the children's performance of this task (see Bradley \& Bryant, 1983). Where Mauchly's test indicated a departure from the assumption of sphericity, Huynh-Feldt and Greenhouse-Geisser corrections, as appropriate, were applied. Follow-up pairwise comparisons used Bonferroni correction.

\section{[TABLE 1 ABOUT HERE]}

Phonological oddity task. As this task required children to select the correct answer from four possible choices, the likelihood of them selecting the correct answer by chance was 6 out of 24 (or 2 out of 8 on each sub-component). None of the total mean scores were below this level 
although accuracy in the first-sound-different condition at Stage 1 was, rising above this threshold from Stage 2 onwards.

The data were analyzed in a 5 (Testing Stage) x 3 (Position of Odd Sound Out) repeatedmeasures analysis of variance although Mauchley's test indicated that the assumption of sphericity had been violated for testing stage, $X^{2}(9)=55.78 ; p<.001$. Therefore, degrees of freedom were corrected using the Huynh-Feldt correction $(\varepsilon=.81)$. The results revealed a significant effect of testing stage, $F(3.25,318.17)=3.05 ; p=.025$, partial $\eta^{2}=.03$, such that performance improved from Stages 1 to $2: t(140)=5.90, p<.001,3$ to $4: t(106)=2.53, p=.013$, and 4 to $5: t(102)=5.35$, $p<.001$. There was a main effect of position of odd-sound-out, $F(2,196)=4.43 ; p=.01$, partial $\eta^{2}=.04$, with poorer performance when this was in the first position than when it was in the middle position $(p<.001)$ or last position $(p<.001)$. There was also a significant interaction between testing stage and position of odd-sound-out, $F(8,784)=2.03 ; p=.04$, partial $\eta^{2}=.02$. At Stages 1 and 2, performance was better in the middle-sound-different (MSD) condition than in the lastsound-different (LSD) condition, Stage 1: $t(141)=3.54, p<.001$; Stage 2: $t(141)=2.48, p=.01$, while at Stage 5, performance was better in the LSD condition than in the MSD condition, $t(102)=$ $2.45, p<.02$. At all stages, performance in the first-sound-different (FSD) condition was poorer than in the MSD condition (Stages 1 to 4: $p$ values <.001; Stage 5: $t(102)=.34, p=.021$ ), or the LSD condition (all $p$ values $<.001$ ).

Phonological memory. In the digit span data, using Huynh-Feldt correction for nonsphericity, $X^{2}(9)=31.01 ; p=.001 ; \varepsilon=.91$, there was a significant main effect of testing stage, $F(3.64,363.89)=49.67 ; p<.001$, partial $\eta^{2}=.33$. This reflected improvements in task performance between each of the first four stages (all $p$ values $<.01$ ).

Block design. Analysis of the block design scores, using a Greenhouse-Geisser correction for non-sphericity of variance, $X^{2}(9)=161.60 ; p<.001 ; \varepsilon=.53$, revealed a significant effect of testing stage, $F(2.12,214.32)=99.11 ; p<.001$, partial $\eta^{2}=.50$; this reflected improvements in performance from Stage 2 onwards (all $p$ values $<.001$ ). 
Matching letter-like forms. This task required the children to chose the correct answer from six over 15 trials; a mean score of 2.5 could, therefore, be obtained by chance. The means in Table 1 show that most children performed consistently and incrementally above this level. As these data did not meet sphericity requirements, $X^{2}(9)=42.63 ; p<.001$, degrees of freedom were adjusted (Huynh-Feldt $\varepsilon=.85)$. Analysis yielded a significant effect of testing stage, $F(3.41$, $341.06)=89.65 ; p<.001$, partial $\eta^{2}=.47$, with improvement in accuracy between each stage (all $p$ values < .001).

Single word reading. As Table 1 shows, although all of the children were unable to read at the time of the first two testing stages, they made consistent improvements once reading instruction had begun at school three months prior to the third testing stage. By Stage 3, the number of children scoring zero on the reading test was $62.2 \%$, and this figure decreased to $21.5 \%$ and $7.8 \%$ at Stages 4 and 5. Analysis of the reading scores from Stage 3 onwards, using the Huyhn-Feldt correction for non-sphericity, $X^{2}(2)=34.55 ; p<.001 ; \varepsilon=.80$, revealed a main effect of testing stage, $F(1.58$, $156.17)=58.14 ; p<.001$, partial $\eta^{2}=.37$; this reflected significant improvements in reading ability between each stage (all $p$ values $<.001$ ).

\section{Correlations Between the Measures at Each Testing Stage}

Correlations between performance on the phonological oddity task, the measures of phonological memory, block design, matching letter-like forms and single word reading across the five testing stages are shown in Table 2. Bivariate correlations are presented below the diagonal, partial correlations controlling for age at time of testing are above the diagonal. While performance on the middle-sound-different and last-sound-different tasks correlated significantly (although not perfectly) throughout the five testing stages, correlations between these measures and performance on the first-sound-different task are less stable. Digit span correlated sporadically with phonological awareness measures across the stages while significant correlations are seen between performance on the block design and letter-like forms tasks, both measures of visual processing. Once reading began to develop, it correlated significantly with digit span and with performance in the middle- 
sound-different, block design and matching letter-like forms tasks at every stage. It also correlated with performance in the first-sound-different and last-sound-different tasks from Stage 4.

\section{[TABLE 2 ABOUT HERE]}

\section{Did the Relationships Between these Skills Change Over Time?}

To investigate changing relationships between the cognitive variables and reading ability across time, cross-lagged correlations were calculated across contiguous stages of testing (see Figure 1). Measuring pairs of variables (X and $\mathrm{Y}$ ) across successive time points yields pairs of autocorrelations between $X_{1}$ and $X_{2}$ (Figure 1, part "a"), and between $Y_{1}$ and $Y_{2}$ (Figure 1, part "b"); pairs of synchronous correlations between $\mathrm{X}_{1}$ and $\mathrm{Y}_{1}$, and $\mathrm{X}_{2}$ and $\mathrm{Y}_{2}$ (Figure 1, parts "c" and “d”); and pairs of autoregressive cross-lagged correlations between $\mathrm{Y}_{1}$ and $\mathrm{X}_{2}$ whilst controlling for the effect of $X_{1}$ (Figure 1, part "e"), and between $X_{1}$ and $Y_{2}$ whilst controlling for the pre-existing effect of $Y_{1}$ (Figure 1, part "f").

Autoregressive cross-lagged analysis is useful for examining reciprocal relationships within a data set where the score at each time $(t)$ depends upon the score at the preceding time $(t-l)$. It also enables us to explore plausible causal pathways between each variable at Time $\mathrm{x}$ and reading ability at Time $x+1$, and between reading ability at Time $\mathrm{x}$ and each other variable at Time $\mathrm{x}+1$. Other forms of analysis (e.g., growth curve analysis, multiple regression) are available, but cross-lagged analysis has been used widely in the literature in the analysis of longitudinal data (e.g., de Lange, Taris, Kompier, Houtman, \& Bongers, 2003; Hong, You, Kim, \& Kim, 2008; Sikora, Moore, Greenberg, \& Grunberg, 2008).

In addition to partialling out pre-existing effects of these key variables, we also partialled out age from the $X_{1}-X_{2}, Y_{1}-Y_{2}, X_{1}-Y_{1}$, and $X_{2}-Y_{2}$ correlations, and block design score from all analyses to control for the effects of general non-verbal intelligence. Digit span score was partialled out of the analysis of the phonological oddity task data to control for short-term memory; this task necessarily includes a strong memory requirement as the children hold the words in memory while they identify the odd sound out. Total score on the phonological oddity task was partialled out of 
the analysis of the digit span data; as reported earlier, some researchers suggest that phonological memory and phonological ability exert independent influences over reading while others argue that once the variance predicted by phonological awareness is controlled for, the remaining variance predicted by phonological memory is minimal. We sought to examine these effects. In the majority of cases, removing these covariates changed the correlation coefficients by less than .1 , and in no case did this change the significance of the relationship.

\section{[FIGURE 1 ABOUT HERE]}

To disentangle the cross-lagged correlations, and to infer causal influences between variables (see Eldredge, Quinn, \& Butterfield, 1990), it is necessary to calculate the RozelleCampbell baseline estimate: $\left(\left(r \mathrm{X}_{1} \mathrm{Y}_{1}+r \mathrm{X}_{2} \mathrm{Y}_{2}\right) / 2\right) *\left(\left(\left(r \mathrm{X}_{1} \mathrm{Y}_{2}\right)^{2}+\left(r \mathrm{X}_{1} \mathrm{Y}_{2}\right)^{2}\right) / 2\right)^{1 / 2}($ Rozelle \& Campbell, 1969; also Roberts \& McCombs, 1994). This formula gives an estimate that the correlation occurred by chance. If one of the observed correlations exceeds this value while the other does not then we can conclude that one variable influenced the other but the reverse was not true. If both cross-lagged correlations exceed this value then we can conclude that each variable reciprocally influenced the other. However, before a cross-lagged correlation can be interpreted as reflecting a causal relationship between variables, it is necessary to test for the equality of the correlations. To do this we calculate a modified version of the Pearson-Filon statistic for dependent correlations based on Fisher's $z$ transformation ${ }^{1}$ (the ZPF; see Raghunathan, Rosenthal, \& Rubin, 1996).

As reading ability was only present from Stage 3, cross-lagged correlations could only be computed from this stage onwards. Rozelle-Campbell baseline estimates and Pearson-Filon statistics were calculated for each pair of correlations based on within-time and within-variable correlations.

\section{Reading Development and Phonological Processing Ability}

As Figure 2 shows, partialled cross-lagged correlations revealed significant positive relationships between alliterative awareness (FSD) at Stage 3 and reading at Stage 4, $r(102)=.25, p$ $=.01$, and between reading at Stage 3 and FSD at Stage $4, r(102)=.21, p=.03$. Both correlations 
exceeded the Rozelle-Campbell baseline (.04) reflecting their reciprocal relationship, but they did not differ significantly from each other, $Z P F=-.32, p=.75$. From Stage 4 to Stage 5 , reading at Stage 4 correlated significantly with FSD at Stage $5, r(97)=.20, p<.05$, but FSD at Stage 4 failed to correlate significantly with reading at Stage $5, r(97)=.02, p=.83$. This latter correlation failed to meet the baseline estimate (.13). The two cross-lagged correlations did not differ significantly, $Z P F=1.42, p=.23$

\section{[FIGURE 2 ABOUT HERE]}

Figure 3 illustrates the data from the phoneme awareness (MSD) condition of the oddity task. As this Figure shows, phoneme awareness at Stage 2 correlated significantly with reading at Stage $3, r(103)=.26, p<.01$, but this influence was not sustained across subsequent stages once the effect of pre-existing reading ability was partialled out. The cross-lagged correlation between MSD at Stage 3 and reading at Stage 4 was non-significant, $r(102)=-.03, p=.78$, and it failed to reach the Rozelle-Campbell baseline (.20) suggesting that MSD at Stage 3 exerted no independent influence over reading at Stage 4. However, reading at Stage 3 did correlate significantly with MSD at Stage $4, r(102)=.39, p<.001$, accounting for $15 \%$ of the variability in phoneme awareness at the end of grade one, and it was significantly different from its cross-lagged partner, $Z P F=3.40, p$ $<.001$. A similar pattern was seen between Stages 4 and 5: while the correlation between MSD at Stage 4 and reading at Stage 5 was non-significant, $r(97)=.06, p=.57$, and below the level of the Rozelle-Campbell baseline (.20), the cross-lagged correlation between reading at Stage 4 and MSD at Stage 5 was significant, $r(97)=.24, p<.02$, but it was not significantly different from its crosslagged partner, $Z P F=1.70, p=.09$.

\section{[FIGURE 3 ABOUT HERE]}

A comparison of the relationship between reading ability and score in the LSD condition of the oddity task (illustrated in Figure 4) again revealed that the relationship between reading and subsequent phonological awareness is stronger than the relationship in the opposite direction. 
While the cross-lagged correlation between LSD at Stage 3 and reading at Stage 4 was nonsignificant, $r(102)=.11, p=.25$, the correlation between reading at Stage 3 and LSD at Stage 4 was significant, $r(102)=.20, p<.04$; both exceeded the Rozelle-Campbell baseline (.09). Similarly, between Stages 4 and 5 the LSD-reading correlation was non-significant, $r(97)=.01, p=.95$, but also below the Rozelle-Campbell baseline (.17), while the reading-LSD correlation was significant, $r(97)=.33, p<.001$, accounting for $10 \%$ of the variability in rhyme awareness in grade two, and above the Rozelle-Campbell baseline. As the solid arrow in Figure 5 indicates, the relationship between reading at Stage 4 and LSD at Stage 5 was significantly greater than the converse relationship, $Z P F=2.84 ; p<.001$.

\section{Reading Development and Phonological Memory}

As Figure 5 shows, digit span at each stage correlated significantly with subsequent reading ability even when the influence of current reading ability and general non-verbal intelligence were partialled out. The cross-lagged correlation between digit span at Stage 3 and reading at Stage 4 was significant, $r(101)=.23, p=.018$, as was the correlation between reading at Stage 3 and digit span at Stage $4, r(101)=.21, p=.03$. Both exceeded the Rozelle-Campbell baseline (.13). However, the two correlations did not differ significantly from each other, $Z P F=-.16, p=.87$. A slightly different pattern emerged between Stages 4 and 5. While the correlation between digit span at Stage 4 and reading at Stage 5 was significant, $r(94)=.29, p<.01$, accounting for almost $9 \%$ of the variability in reading ability in grade two, the correlation between reading at Stage 4 and digit span at Stage 5 was not significant, $r(96)=.04, p=.68$. This latter correlation failed to meet the RozelleCampbell baseline (.25), and the two correlations differed significantly from each other, ZPF = $2.25, p=.02$

\section{[FIGURE 5 ABOUT HERE]}

\section{Reading Development and Visual Processing Ability}

Figure 6 shows a significant positive correlation between block design score at Stage 2 and emergent reading ability at Stage $3, r(104)=.46, p<.001$, accounting for $21 \%$ of the variance in 
reading ability in grade one, and also between block design score at Stage 3 and reading ability at Stage $4, r(103)=.22, p<.03$. This correlation was significantly larger, $Z P F=-2.50, p=.01$, than the cross-lagged correlation between reading at Stage 3 and block design score at Stage $4, r(103)=$ $-.05, p=.62$. Furthermore, this correlation failed to reach the baseline estimate (.21). No significant effects were found between these two variables across the final two stages: from block design at Stage 4 to reading at Stage $5, r(98)=.10, p=.32$, or from reading at Stage 4 to block design at Stage $5, r(99)=.17, p=.08$. Both failed to reach the Rozelle-Campbell baseline (.28), and the correlations did not differ significantly from each other, $Z P F=.80, p=.42$.

\section{[FIGURE 6 ABOUT HERE]}

A slightly different pattern of results emerged from the matching letter-like forms data (Figure 7). This measure taken at Stage 2, before the children could read, correlated significantly with emergent reading ability at Stage $3, r(103)=.20, p<.04$. The Stage 3 matching letter-like forms scores correlated with reading ability at Stage $4, r(102)=.29, p<.01$, accounting for $8 \%$ of the variance in reading ability, and the Stage 4 matching letter-like forms scores correlated significantly with reading ability at Stage $5, r(98)=.21, p=.03$, although this correlation failed to meet the baseline estimate (.22). No significant relationships were found in the correlations between reading at Stage 3 and matching letter-like forms score at Stage $4, r(102)=-.03, p=.76$, or between reading at Stage 4 and matching letter-like forms score at Stage $5, r(99)=.05, p=.63$, both of which failed to reach their Rozelle-Campbell baselines. In each of these cases the cross-lagged correlations from matching letter-like forms scores to subsequent reading ability were greater than those from reading ability to subsequent matching letter-like forms scores but only the former difference was significant, $Z P F=-2.66, p=.01$.

\section{[FIGURE 7 ABOUT HERE]}

\section{Discussion}

This study examined the cognitive precursors of reading in young children from pre-literacy to early reading competence. While other studies have investigated changes in the relationship 
between various cognitive abilities and reading, this study recruited a large sample of children, all pre-readers at the start of the study, thus conforming to Wagner and Torgesen's (1987) suggestion that the maximally informative longitudinal study should commence with a sample of children proven to be non-readers. It then re-tested them at regular intervals across the period during which they acquired early reading skills. Analysis of these data explored the bi-directional relationships between each cognitive skill and reading ability across contiguous testing stages while ensuring that any pre-existing influence of one skill on the other was statistically removed.

Performance on the block design task at Stages 2 and 3 correlated with reading skills at Stages 3 and 4, and performance on the matching letter-like forms task correlated significantly with subsequent reading ability across all stages. Thus, it would appear that the ability to analyze visual forms is important for the early acquisition of reading, and early visual analysis skills-particularly the ability to distinguish between letter-like shapes-may enhance the efficacy of elementary reading instruction (Badian, 2001; Feagans \& Merriwether, 1990). A similar finding has been reported for first-grade children learning to read Chinese in that visual ability (measured by a visual paired associates test) correlated with reading ability at the end of the first year of schooling, although this effect disappeared when IQ was partialled out. This may be explained by the fact that IQ was determined using Raven's Matrices. By partialling out Raven's IQ, therefore, the authors removed the influence of the visual ability that the study attempted to explore (Huang \& Hanley, 1997). In the current study, non-verbal intelligence was indexed using block design score ${ }^{2}$, and while removing the effect of this variable from our other measure of visual processing ability - matching letter-like forms - reduced its relationship with current and future reading ability, it failed to eliminate it. Vellutino et al.'s (2007) cross-sectional study of reading development in children from grades 2 and 3, and from grades 6 and 7 found only weak relationships between visual abilities and reading, and these disappeared completely in the older children following bootstrap analyses. It might be predicted that a similar pattern would emerge from the current sample of children if they 
were re-tested in later grades. Of greater importance in terms of reading development, beyond the initial stages, is phonological processing ability.

Significant correlations were observed between phonological awareness and reading across the course of the study but the three measures displayed slightly different relationships with reading ability. While rhyme awareness (MSD and LSD) correlated significantly with concurrent reading ability at Stages 3,4 and 5, and both measures at Stage 2 correlated with emergent reading ability at Stage 3, word onset awareness (FSD) did not correlate significantly with concurrent reading ability until Stages 4 and 5, and it only correlated with future reading ability at Stage 3 . That is, the relationship between onset awareness and reading ability did not emerge until the children had already acquired some elementary reading skills. A large amount of time is spent in British kindergartens teaching children nursery rhymes and songs which emphasize the rime (e.g., Humpty Dumpty sat on a wall, Humpty D $\underline{\text { umpty }}$ had a great fall) so it is not too surprising that sensitivity to rhyme develops early. By contrast, the ability to distinguish between words on the basis of their onset is much more difficult involving the detection of smaller phonological units, usually single consonants (see Bradley, 1980; Bradley \& Bryant, 1983; Goswami, 1986; Wimmer et al., 1994). Taken together, these findings indicate that the onset detection and rhyme detection subcomponents of the oddity task tap different aspects of phonological awareness-preschool rhyme awareness is related to emergent reading ability while word onset awareness is related to reading ability at the end of grade 1-but also that once the effect of these early reading skills have been removed from the relationship, much of the influence of phonological awareness on later reading ability disappears.

It should be noted, however, that the relationship between young children's phonological awareness and their later reading ability is closely correlated with their letter knowledge: Alongside phonological awareness, letter knowledge is considered to be one of the most important predictors of subsequent reading ability (Denton \& West, 2002; Mann \& Foy, 2003; Molfese, Modglin, Beswick, Neamon, Berg, Berg, \& Molnar, 2006). Unfortunately, however, the measurement of 
letter knowledge (beyond the matching of letter-like forms) was omitted from the current study, so it is possible that some of the variance in reading ability that we have attributed to phonological awareness may in fact be due to the children's earlier letter knowledge.

While the prospective influence of phonological awareness diminished once reading ability was partialled out, reciprocal influence remained between reading ability and subsequent onset and rhyme awareness across the study. Thus, although evidence attests to the primacy of phonological awareness in the early stages of reading development (e.g., Lonigan et al., 2000; Mann, 1991; Vellutino et al., 2007; Ziegler et al., 2010), the acquisition of early literacy skills promotes subsequent phonological awareness by allowing children to explore the phonological principles which underlie alphabetic orthography. Many longitudinal studies of children's development (e.g., Bryant, Bradley, Maclean, \& Crossland, 1989; Carroll et al., 2003; Nauclér \& Magnusson, 1999; Stuart \& Coltheart, 1988), however, fail to partial out pre-existing effects of early reading when assessing the importance of early phonological ability. As such, there is a danger of overemphasizing the relationship between early phonological awareness and later reading ability (in the current study, cross-lagged correlations calculated without partialling out pre-existing abilities were much higher than the partialled correlations reported here). Support for this suggestion is provided by Wagner and Torgesen's (1987) re-analysis of Lundberg, Olofsson and Wall's (1980) data: the substantial partial correlations reported by Lundberg et al., between kindergarten phonological awareness and later reading scores, mostly dropped to zero when pre-existing reading ability was controlled (cf. Huang \& Hanley, 1997). To examine fully the relationship between reading and other cognitive skills as they develop, it is necessary to measure all variables at every stage and to eliminate abilities that have aggregated prior to this time.

The variable that emerged from the present study as having the most enduring influence over subsequent reading ability was phonological memory. Digit span correlated significantly with current reading ability at Stages 3, 4, and 5, and with future reading ability at Stages 2, 3, and 4, even when the influence of previous reading ability was removed. Phonological short-term memory 
is important for learning grapheme-phoneme correspondences which allow children to decode unfamiliar words. It acts as a buffer to store the individual phonemes generated by graphemephoneme decoding and it enables novice readers to build up a sight vocabulary of familiar, written words (Alloway et al., 2005; Baddeley, Gathercole, \& Papagno, 1998). However, it should be noted that much of this relationship between phonological memory and reading development may be explained by the wider effects of phonological awareness. Phonological memory correlated significantly with phonological awareness in Stages 2, 3, 4, and 5 (although the correlations were weak to moderate and rather inconsistent), and others have reported a high degree of shared predictive variance between verbal short-term memory and phonological processing skill (de Jong \& van der Leij, 1999; Parrila et al., 2004). These data would seem to support the view that while phonological memory and phonological awareness are both influenced by common phonological processes, they actually reflect independent cognitive constructs and make independent contributions to the efficacy of reading development (Alloway et al., 2005; Hecht, Torgesen, Wagner, \& Rashotte, 2001).

\section{Summary and Concluding Comments}

In a longitudinal study of young children we found significant synchronous and partial cross-lagged correlations between visual processing skill, phonological memory, phonological awareness, and emergent reading ability. This study addressed short-comings of many previous studies of reading development: it is one of the few longitudinal studies to have tested large numbers of children, repeatedly, over a critical period of time during which they developed from being pre-readers to being early readers; it assessed key cognitive skills and, importantly, it controlled for reciprocal causality between variables at every stage.

Future studies might explore reading development across languages with different orthographic consistency. Young children whose native languages are consistent (e.g., Spanish or Finnish) acquire phonological recoding skills far more rapidly than do children whose native languages are inconsistent (e.g., English or Danish)(Seymour, Aro, \& Erskine, 2003). Furthermore, 
those whose languages are consistent quickly come to depend on these phonological recoding skills for accurate reading of familiar and unfamiliar words, while children whose languages are inconsistent cannot rely so heavily on grapheme-phoneme recoding at the small grain size if they are to cope with the orthographic vagaries of their languages. It is to be expected, therefore, that these groups of children will display somewhat different relationships between their visual, phonological, memory, and reading skills across the first few years of their school lives.

Future studies might also follow children's development over longer periods of time to determine the extent to which visual skills, phonological awareness, and phonological memory continue to interact with reading development as children grow older. Using such information, it might be possible to screen children for early impairments in these skills, even before they start formal education, and to identify children who are "at risk" for future reading problems. Evidence from children and adults with developmental dyslexia has pointed to the importance of phonological awareness and phonological short-term memory skills in these individuals' reading difficulties. There is almost universal agreement that at the very heart of dyslexia is a fundamental impairment in phonological processing, as manifested by difficulty with recognizing rhyming words, repeating non-words or performing Spoonerism tasks, for example (see Brunswick, 2009; Démonet, Taylor \& Chaix, 2004; Habib, 2000). Dyslexic readers also typically demonstrate reduced phonological short-term memory span for various types of stimuli including letter strings, unrelated word strings, and strings of digits (see Brunswick et al., 1999; Kibby, 2009; Paulesu et al., 2001). Such evidence speaks to the central and enduring importance of phonological processing and phonological memory skills for skilled reading development. In line with the current study's findings regarding the relatively reduced role played by visual processing skills in the later stages of reading development relative to the earlier stages, visuospatial difficulties are not always found in children and adults with dyslexia (Jeffries and Everatt, 2004; Kibby, 2009; Paulesu et al, 2001). In fact, a recent study by Brunswick, Martin and Marzano (2010) even reported visuospatial advantage in dyslexic men. On the basis of their review of phonological, auditory, and visual 
abilities in adult developmental dyslexic readers, Ramus and colleagues reported that whereas very few of their participants exhibited visual difficulties, all had phonemic difficulties (Ramus et al., 2003).

Providing focused training and support in these key skills at an early stage might help to alleviate some potential reading problems before they start. For example, a small number of intervention studies have demonstrated that young children who receive explicit instruction in phonological processing subsequently display improvement in their reading skills (Byrne, FieldingBarnsley, \& Ashley, 2000; Casalis \& Colé, 2009; Temple et al., 2003). Our data provide some indirect support for the proposition that early training in the specific cognitive skills that are significantly associated with literacy development may greatly assist children's ability to learn to read.

\section{References}

Abbott, R. D., Berninger, V. W., \& Fayol, M. (2010). Longitudinal relationships of level of language in writing and between writing and reading in grades 1 to 7 . Journal of Educational Psychology, 102, 2, 281-298.

Ackerman, P. T., \& Dykman, R. A. (1993). Phonological processes, confrontational naming, and immediate memory in dyslexia. Journal of Learning Disabilities, 26, 9, 597-609.

Adams, M. J. (1990). Beginning to read: Thinking and learning about print. Cambridge, MA: MIT Press.

Alloway, T. P., Gathercole, S. E., Adams, A. -M., Willis, C. S., Eaglen, R., \& Lamont, E. (2005). Working memory and phonological awareness as predictors of progress towards early learning goals at school entry. British Journal of Developmental Psychology, 23, 417-426.

Baddeley, A. D. (1986). Working memory. Oxford: Oxford University Press.

Baddeley, A., Gathercole, S., \& Papagno, C. (1998). The phonological loop as a language learning device. Psychological Review, 105, 158-173. 
Badian, N. A. (1994). Preschool prediction: orthographic and phonological skills and reading. Annals of Dyslexia, 44, 3-25.

Badian, N. A. (2000). Do preschool orthographic skills contribute to prediction of reading? In N. Badian (Ed.) Prediction and prevention of reading failure (pp. 31-36). Timonium, MD: York Press.

Badian, N. A. (2001). Phonological and orthographic processing: Their roles in reading prediction. Annals of Dyslexia, 51, 179-202.

Bowyer-Crane, C., Snowling, M. J., Duff, F. J., Fieldsend, E., Carroll, J. M., Miles, J., Götz, K., \& Hulme, C. (2008). Improving early language and literacy skills: Differential effects of an oral language versus a phonology with reading intervention. Journal of Child Psychology and Psychiatry, 49, 422-432.

Bradley, L. (1980). Assessing reading difficulties: A diagnostic and remedial approach. London: Macmillan Education.

Bradley, L., \& Bryant, P. E. (1983). Categorising sounds and learning to read - a causal connection. Nature, 301, 419-421.

Bradley, L., \& Bryant, P. E. (1985). Rhyme and reason in reading and spelling. International Academy for Research in Learning Disabilities Monograph Series. Ann Arbour: University of Michigan Press.

Brunswick, N. (2009). A Beginner's Guide to Dyslexia. Oxford: Oneworld Publications.

Brunswick, N., Martin, G. N., \& Marzano, L. (2010). Visuospatial superiority in developmental dyslexia: myth or reality? Learning and Individual Differences, 20, 421-426.

Brunswick, N., McCrory, E., Price, C., Frith, C. D. \& Frith, U. (1999). Explicit and implicit processing of words and pseudowords by adult developmental dyslexics: a search for Wernicke's Wortschatz? Brain, 122, 1901-1917.

Bryant, P., Bradley, L., Maclean, M., \& Crossland, J. (1989). Nursery rhymes, phonological skills and reading. Journal of Child Language, 16, 407-428. 
Byrne, B., Delaland, C., Fielding-Barnsley, R., Quain, P., Samuelsson, S., Høien, T., Corley, R., DeFries, J., Wadsworth, S., Willcutt, E., \& Olson, R. (2002). Longitudinal twin study of early reading development in three countries. Preliminary results. Annals of Dyslexia, 52, 49-73.

Byrne, B., Fielding-Barnsley, R., \& Ashley, L. (2000). Effects of preschool phoneme identity training after six years: outcome level distinguished from rate of response. Journal of Educational Psychology, 92, 4, 659-667.

Cardoso-Martins, C., \& Pennington, B. F. (2004). The relationship between phoneme awareness and rapid serial naming skills and literacy acquisition: The role of developmental period and reading ability. Scientific Studies of Reading, 8, 1, 27-52.

Carroll, J. M., Snowling, M. J., Hulme, C., \& Stevenson, J. (2003). The development of phonological awareness in preschool children. Developmental Psychology, 39, 5, 913-923.

Casalis, S., \& Colé, P. (2009). On the relationship between morphological and phonological awareness: Effects of training in kindergarten and in first-grade reading. First Language, 29, $1,113-142$

Chapman, J.W., \& Tunmer, W.E. (1997). A longitudinal study of beginning reading achievement and reading self-concept. British Journal of Educational Psychology, 67, 279-291.

de Jong, P. F., \& Olson, R. K. (2004). Early prediction of letter knowledge. Journal of Experimental Child Psychology, 88, 254-273.

de Jong, P. F., \& van der Leij, A. (1999). Specific contributions of phonological abilities to early reading acquisition: results from a Dutch latent variable longitudinal study. Journal of Educational Psychology, 91, 450-476.

de Lange, A. H., Taris, T. W., Kompier, M. A. J., Houtman, I. L. D., \& Bongers, P. M., (2003). The very best of the Millenium: Longitudinal research and the demand-control-(support) model. Journal of Occupational Health Psychology, 8, 282-305. 
Démonet, J.-F., Taylor, M. J., \& Chaix, Y. (2004). Developmental dyslexia. Lancet, 363 (9419), $1451-1460$.

Denton, K., \& West, J. (2002). Children's reading and mathematics achievement in kindergarten and first grade. Washington, DC: US Department of Education, National Center for Educational Statistics.

Duncan, L.G., \& Seymour, P.H.K. (2000). Socio-economic differences in foundation-level literacy. British Journal of Psychology, 91, 145-166.

Eldredge, J. L., Quinn, B., \& Butterfield, D. D. (1990). Causal relations between phonics, reading comprehension, and vocabulary achievement in the second grade. Journal of Educational Research, 83, 4, 201-214.

Elliott C. (1983). British Ability Scales. Manual 2. Technical Handbook. Windsor: NFER-Nelson.

Elliott, C.D., Murray, D.J., \& Pearson, L.S. (1983). British Ability Scales. Windsor: NFER-Nelson.

Ellis, N., \& Large, B. (1988). The early stages of reading: A longitudinal study. Applied Cognitive Psychology, 2, 47-76.

Feagans, L. V., \& Merriwether, A. (1990). Visual discrimination of letter-like forms and its relationship to achievement over time in children with learning disabilities. Journal of Learning Disabilities, 23, 417-425.

Frith, U. (1985). Beneath the surface of developmental dyslexia. In K. E. Patterson, J. C. Marshall \& M. Coltheart (Eds.), Neuropsychological and cognitive studies of phonological reading (pp. 301-330). Lawrence Erlbaum Associates: Hillsdale, NJ.

Gathercole, S. E., \& Baddeley, A. D. (1989). Evaluation of the role of phonological STM in the development of vocabulary in children: A longitudinal study. Journal of Memory and Language, 28, 200-213.

Gathercole, S. E., Service, E., Hitch, G. J., Adams, A. -M., \& Martin, A. J. (1999). Phonological short-term memory and vocabulary development: Further evidence on the nature of the relationship. Applied Cognitive Psychology, 13, 65-77. 
Gathercole, S. E., Tiffany, C., Briscoe, J., Thorn, A. S. C., \& ALSPAC Team (2005). Developmental consequences of poor phonological short-term memory function in childhood: A longitudinal study. Journal of Child Psychology and Psychiatry, 46, 598-611.

Gathercole, S. E., Willis, C., Emslie, H., \& Baddeley, A. D. (1991). The influences of number of syllables and wordlikeness on children's repetition of nonwords. Applied Psycholinguistics, $12,349-367$.

Gipstein, M., Brady, S. A., \& Fowler, A. (2000). Questioning the role of syllables and rimes in early phonological awareness. In N. A. Badian (Ed.) Prediction and prevention of reading failure (pp. 179-216). Baltimore, MD: York Press.

Goodman, K.S. (1986). What's whole in whole language? Portsmouth, NH: Heinemann

Goswami, U. (1986). Children's use of analogy in learning to read: A developmental study. Journal of Experimental Child Psychology, 42, 73-83.

Gottardo, A., Stanovich, K. E., \& Siegel, L. S. (1996). The relationships between phonological sensitivity, syntactic processing, and verbal working memory in the reading performance of third-grade children. Journal of Experimental Child Psychology, 63, 563-582.

Habib, M. (2000). The neurobiological basis of developmental dyslexia. Brain, 123, 2373-2399.

Hansen, J., \& Bowey, J. A. (1994). Phonological analysis skills, verbal working memory, and reading ability in second-grade children. Child Development, 65, 938-950.

Hatcher, P. J., \& Hulme, C. (1999). Phonemes, rhymes, and intelligence as predictors of children's responsiveness to remedial reading instruction: evidence from a longitudinal intervention study. Journal of Experimental Child Psychology, 72, 130-153.

Hecht, S. A., Torgesen, J. K., Wagner, R. K., \& Rashotte, C. A. (2001). The relations between phonological processing abilities and emerging individual differences in mathematical computation skills: A longitudinal study from second to fifth grades. Journal of Experimental Child Psychology, 79, 192-227. 
Hong, S., You, S. Kim, E.-J., \& Kim, J. (2008). Multivariate autoregressive cross-lagged modelling of the reciprocal longitudinal relationship between perceived control and academic achievement. Psychological Reports, 102, 873-883.

Huang, H. S., \& Hanley, J. R. (1997). A longitudinal study of phonological awareness, visual skills and Chinese reading acquisition among first-graders in Taiwan. International Journal of Behavioral Development, 20, 2, 249-268.

Hulme, C. (1988). Short-term memory development and learning to read. In M. Gruneberg, P. Morris, \& R. Sykes (Eds.), Practical aspects of memory: Current research and issues: Vol. 2. Clinical and educational implications (pp. 234-271). Chichester, England: Wiley.

Jeffries, S., \& Everatt, J. (2004). Working memory: its role in dyslexia and other specific learning difficulties. Dyslexia, 10, 3, 196-214.

Kibby, M. Y. (2009). Memory functioning in developmental dyslexia: An analysis using two clinical memory measures. Archives of Clinical Neuropsychology, 24, 3, 245-254.

Kirby, J. R., Parrila, R. K., \& Pfeiffer, S. L. (2003). Naming speed and phonological awareness as predictors of reading development. Journal of Educational Psychology, 95, 3, 453-464.

Kokis, J., Macpherson, R., Toplak, M., West, R.F., \& Stanovich, K.E. (2002). Heuristic and analytic processing: Age trends and associations with cognitive ability and cognitive styles. Journal of Experimental Child Psychology, 83, 26-52.

Lervåg, A., Bråten, I., \& Hulme, C. (2009). The cognitive and linguistic foundations of early reading development: A Norwegian latent variable longitudinal study. Developmental Psychology, 45, 3, 764-781. 
Lonigan, C. J. (2007). Vocabulary development and the development of phonological awareness skills in preschool children. In R. K. Wagner, A. E. Muse, \& K. R. Tannenbaum (Eds.), Vocabulary acquisition: Implications for reading comprehension (pp. 15-31). New York, USA: The Guilford Press.

Lonigan, C. J., Burgess, S. R., \& Anthony, J. L. (2000). Development of emergent literacy and early reading skills in preschool children: evidence from a latent-variable longitudinal study. Developmental Psychology, 36, 5, 596-613.

Lundberg, I., Olofsson, A., \& Wall, S. (1980). Reading and spelling skills in the first school years predicted from phonemic awareness skills in kindergarten. Scandinavian Journal of Psychology, 21, 159-173.

Macmillan, B. (2002). Rhyme and reading: A critical review of the research methodology. Journal of Research in Reading, 25, 4-42.

Mann, V. A. (1991). Are we taking too narrow a view of the conditions for development of phonological awareness? In S. A. Brady, \& D. P. Shankweiler (Eds.), Phonological processes in literacy (pp. 55-64). Lawrence Erlbaum Associates: Hillsdale, NJ.

Mann, V. A., \& Foy, J. G. (2003). Phonological awareness, speech development, and letter knowledge in preschool children. Annals of Dyslexia, 53, 149-173.

Mann, V. A., \& Liberman, I. Y. (1984). Phonological awareness and verbal short-term memory: Can they presage early reading success? Journal of Learning Disabilities, 17, 592-598.

McCrory, E., Frith, U., Brunswick, N., \& Price, C. (2000). Abnormal functional activation during a simple word repetition task: a PET study of adult dyslexics. Journal of Cognitive Neuroscience, 12, 5, 753-762

McDougall, S., Hulme, C., Ellis, A., \& Monk, A. (1994). Learning to read: the role of short-term memory and phonological skills. Journal of Experimental Child Psychology, 58, 112-133.

Miles, T. R., Thierry, G., Roberts, J., \& Schiffeldrin, J. (2006). Verbatim and gist recall of sentences by dyslexic and non-dyslexic adults. Dyslexia , 12, 177-194. 
Molfese, V. J., Modglin, A. A., Beswick, J. L., Neamon, J. D., Berg, S. A., Berg, J., \& Molnar, A. (2006). Letter knowledge, phonological processing, and print knowledge: Skill development in nonreading preschool children. Journal of Learning Disabilities, 39, 4, 296-305.

Muter, V., Hulme, C., Snowling, M., \& Stevenson, J. (2004). Phonemes, Rimes, Vocabulary, and Grammatical Skills as Foundations of Early Reading Development: Evidence From a Longitudinal Study. Developmental Psychology, 40, 5, 665-681.

Muter, V., \& Snowling, M. (1998). Concurrent and longitudinal predictors of reading: The role of metalinguistic and short-term memory skills. Reading Research Quarterly, 33, 320-337.

Nauclér, K., \& Magnusson, E. (1999). Reading and writing development. A longitudinal study from preschool to adolescence: Status report. Lund University Department of Linguistics Working Papers, 47, 169-180.

Nampijja, M., Apule, B., Lule, S., Akurut, H., Muhangi, L., Elliott, A. M., \& Alcock, K. J. (2010). Adaptation of Western measures of cognition for assessing 5-year-old semi-urban Ugandan children. British Journal of Educational Psychology, 80, 15-30.

Onatsu-Arvilommi, T., \& Nurmi, J. -E. (2000). The role of task-avoidant and task-focused behaviors in the development of reading and mathematical skills during the first school year: A cross-lagged longitudinal study. Journal of Educational Psychology, 92, 3, 478-491.

Parrila, R. K., Kirby, J. R., \& McQuarrie, L. (2004). Articulation rate, naming speed, verbal shortterm memory, and phonological awareness: Longitudinal predictors of early reading development? Scientific Studies of Reading, 8, 3-26.

Paulesu, E., Démonet, J.-F., Fazio, F., McCrory, E., Chanoine, V., Brunswick, N., Cappa, S. F., Cossu, G., Habib, M., Frith, C. D. and Frith, U. (2001). Dyslexia: Cultural diversity and biological unity, Science, 291, 2165-2167.

Phillips, L. M., Norris, S. P., Osmond, W. C., \& Maynard, A. M. (2002). Relative reading achievement: A longitudinal study of 187 children from first through sixth grades. Journal of Educational Psychology, 94, 3-13. 
Raghunathan, T. E., Rosenthal, R., \& Rubin, D. B. (1996). Comparing correlated but nonoverlapping correlations, Psychological Methods, 1, 178-183.

Ramus, F., Rosen, S., Dakin, S., Day, B. L., Castellote, J. M., White, S., \& Frith, U. (2003). Theories of developmental dyslexia: Insights from a multiple case study. Brain, 126, 841865.

Roberts, M., \& McCombs, M. (1994). Agenda-setting and political advertising: origins of the news agenda. Political Communication, 11, 249-62.

Rohl, M., \& Pratt, C. (1995). Phonological awareness, verbal working memory and the acquisition of literacy. Reading \& Writing, 7, $327-360$.

Roman, A.A., Kirby, J.R., Parrila, R.K., Wade-Woolley, L., \& Deacon, S.H. (2009). Toward a comprehensive view of the skills involved in word reading in Grades 4, 6, and 8. Journal of Experimental Child Psychology, 102, 96-113.

Rozelle, R. M., \& Campbell, D. T. (1969). More plausible rival hypotheses in the cross-lagged panel correlation technique. Psychological Bulletin, 71, 74-80.

Schatschneider, C., Fletcher, J. M., Francis, D. J., Carlson, C., \& Foorman, B. R. (2004)

Kindergarten prediction of reading skills: A longitudinal comparative analysis. Journal of Educational Psychology, 96, 265-282.

Seymour, P. H. K., Aro, M., \& Erskine, J. M. (2003). Foundation literacy acquisition in European orthographies. British Journal of Psychology, 94, 143-174.

Sikora, P., Moore, S., Greenberg, E., \& Grunberg, L. (2008). Downsizing and alcohol use: A crosslagged longitudinal examination of the spillover hypothesis. Work \& Stress, 22, 51-68.

Sprenger-Charolles, L., Siegel, L., Béchennec, D., \& Serniclaes, W. (2003). Development of phonological and orthographic processing in reading aloud, in silent reading and in spelling: A four year longitudinal study. Journal of Experimental Child Psychology, 84, 194-217.

Stahl, S. A., \& Murray, B. A. (1994). Defining phonological awareness and its relationship to early reading. Journal of Educational Psychology, 86, 221-234 
Stanovich, K. E., Cunningham, A. E., \& Cramer, B. (1984). Assessing phonological awareness in kindergarten children: Issues of task comparability. Journal of Experimental Child Psychology, 38, 175-190.

Storch, S. A., \& Whitehurst, G. J. (2002). Oral language and code-related precursors to reading: Evidence from a longitudinal model. Developmental Psychology, 38, 934-947.

Stuart, M., \& Coltheart, M (1988) Does reading develop in a sequence of stages? Cognition, 30, 139-181.

Temple, E., Deutsch, G. K., Poldrack, R. A., Miller, S. L., Tallal, P., Merzenich, M. M., \& Gabrieli, J. D. (2003). Neural deficits in children with dyslexia ameliorated by behavioral remediation: Evidence from fMRI. Proceedings of the National Academy of Sciences, 100, 2860-2865.

Torgesen, J.K., Wagner, R.K., \& Rashotte, C.A. (1994). Longitudinal studies of phonological processing and reading. Journal of Learning Disabilities, 27, 276-286.

Vandervelden, M. C., \& Siegel, L. S. (1995). Phonological recoding and phoneme awareness in early literacy: A developmental approach. Reading Research Quarterly, 30, 854-875.

Vellutino, F. R., Tunmer, W. E., Jaccard, J. J., \& Chen, R. S. (2007). Components of reading ability: Multivariate evidence for a convergent skills model of reading development. Scientific Studies of Reading, 11, 1, 3-32.

Wagner, R. K., \& Torgesen, J. K. (1987). The nature of phonological processing and its causal role in the acquisition of reading skills. Psychological Bulletin, 101, 192-212.

Wimmer, H., Landerl, K., \& Schneider, W. (1994). The role of rhyme awareness in learning to read a regular orthography. British Journal of Developmental Psychology, 12, 469-484.

Windfuhr, K., \& Snowling, M.J. (2001). The relationship between paired associate learning and phonological skills in normally developing readers. Journal of Experimental Child Psychology, 80, 160-173. 
Ziegler, J. C., Bertrand, D., Tóth, D., Csépe, V., Reis, A., Faisca, L., Saine, N., Lyytinen, H., Vaessen, A., \& Blomert, L. (2010). Orthographic depth and its impact on universal predictors of reading: A cross-language investigation. Psychological Science, 21, 4, 551559.

Ziegler, J.C., \& Goswami, U. (2006). Becoming literate in different languages: similar problems, different solutions. Developmental Science, 9, 429-453. 


\section{Footnote 1}

${ }^{1}$ The modified Pearson-Filon statistic is calculated as follows:

$$
\begin{aligned}
Z P F & =\frac{\sqrt{ } n *\left(r \mathrm{X}_{1} \underline{\mathrm{Y}}_{2}-r \mathrm{Y}_{1} \underline{\mathrm{X}}_{2}\right)}{\sqrt{ }\left(1-r \mathrm{X}_{1} \mathrm{Y}_{2}^{2}\right)^{2}+\left(1-r \mathrm{Y}_{1} \mathrm{X}_{2}^{2}\right)^{2}-k \text { where }} \\
k & =\left(r \mathrm{X}_{1} \mathrm{Y}_{1}-r \mathrm{Y}_{1} \mathrm{Y}_{2} * r \mathrm{X}_{1} \mathrm{Y}_{2}\right) *\left(r \mathrm{X}_{2} \mathrm{Y}_{2}-r \mathrm{Y}_{1} \mathrm{Y}_{2} * r \mathrm{Y}_{1} \mathrm{X}_{2}\right) \\
& +\left(r \mathrm{X}_{1} \mathrm{X}_{2}-r \mathrm{X}_{1} \mathrm{Y}_{1} * r \mathrm{Y}_{1} \mathrm{X}_{2}\right) *\left(r \mathrm{Y}_{1} \mathrm{Y}_{2}-r \mathrm{X}_{1} \mathrm{Y}_{1} * r \mathrm{X}_{1} \mathrm{Y}_{2}\right) \\
& +\left(r \mathrm{X}_{1} \mathrm{Y}_{1}-r \mathrm{X}_{1} \mathrm{X}_{2} * r \mathrm{Y}_{1} \mathrm{X}_{2}\right) *\left(r \mathrm{X}_{2} \mathrm{Y}_{2}-r \mathrm{X}_{1} \mathrm{X}_{2} * r \mathrm{X}_{1} \mathrm{Y}_{2}\right) \\
& +\left(r \mathrm{X}_{1} \mathrm{X}_{2}-r \mathrm{X}_{1} \mathrm{Y}_{2} * r \mathrm{X}_{1} \mathrm{Y}_{2}\right) *\left(r \mathrm{Y}_{1} \mathrm{Y}_{2}-r \mathrm{X}_{2} \mathrm{Y}_{2} * r \mathrm{Y}_{1} \mathrm{X}_{2}\right)
\end{aligned}
$$




\section{Footnote 2}

${ }^{2}$ We acknowledge that using block design score as a single proxy measure for general cognitive ability is a limitation of this study. While the block design test is reliable and widely used to assess nonverbal intelligence, it does not in itself provide a comprehensive index of intelligence. Future studies should include a range of tests to tap both verbal and nonverbal IQ. 


\section{Figure captions}

Figure 1. Cross-lagged correlations

Note. $\mathrm{a}$ and $\mathrm{b}=$ autocorrelations between Time 1 and Time $2 ; \mathrm{c}$ and $\mathrm{d}=$ synchronous correlations between variables at each time point; e and $\mathrm{f}=$ partialled cross-lagged correlations

Figure 2. Correlations between score on the first-sound-different condition of the phonological oddity task (onset awareness) and reading score

Note. FSD = first-sound-different; $* p<.05 ; * * p<.01$

Figure 3. Correlations between score on the middle-sound-different condition of the phonological oddity task and reading score

Note. $\mathrm{MSD}=$ middle-sound-different $* *<.05 ; * * p<.01$. The solid diagonal lines indicate that these partial correlations are significantly greater than the cross-lagged partial correlations

Figure 4. Correlations between score on the last-sound-different condition of the phonological oddity task and reading score

Note . LSD $=$ last-sound-different ${ }^{*} p<.05 ; * * p<.01$. The solid diagonal line indicates that this partial correlation is significantly greater than the cross-lagged partial correlation

Figure 5. Correlations between digit span and reading score Note. ${ }^{*} p<0.05 ; * * p<0.01$. The solid diagonal line indicates that this partial correlation is significantly greater than the cross-lagged partial correlation

Figure 6. Correlations between block design scores and reading score 
Note. ${ }^{*} p<.05 ; * * p<.01$. The solid diagonal line indicates that this partial correlation is significantly greater than the cross-lagged partial correlation

Figure 7. Correlations between matching letter-like forms scores and reading score Note. $* p<.05 ; * * p<.01$. The solid line indicates that this partial correlation is significantly greater than the cross-lagged partial correlation 
Time 1

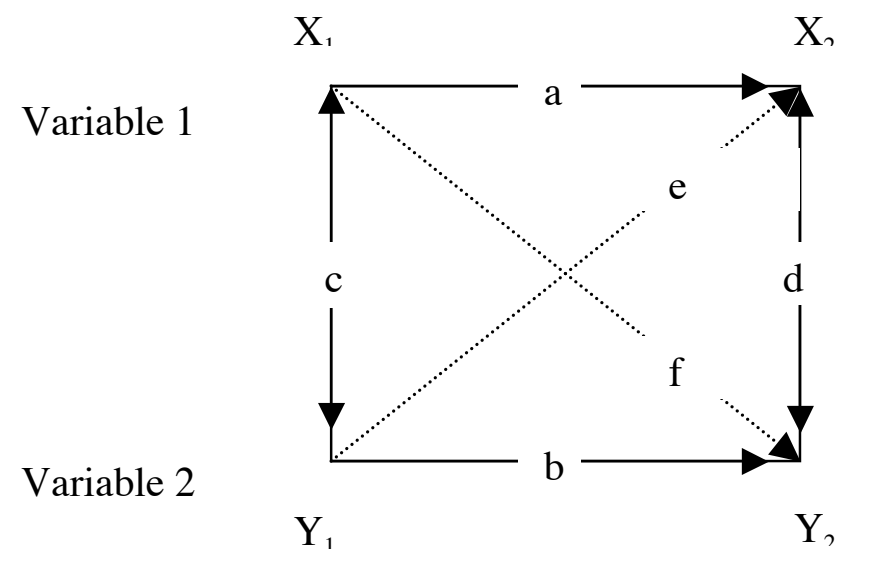

Figure 1.

Time 2

, 


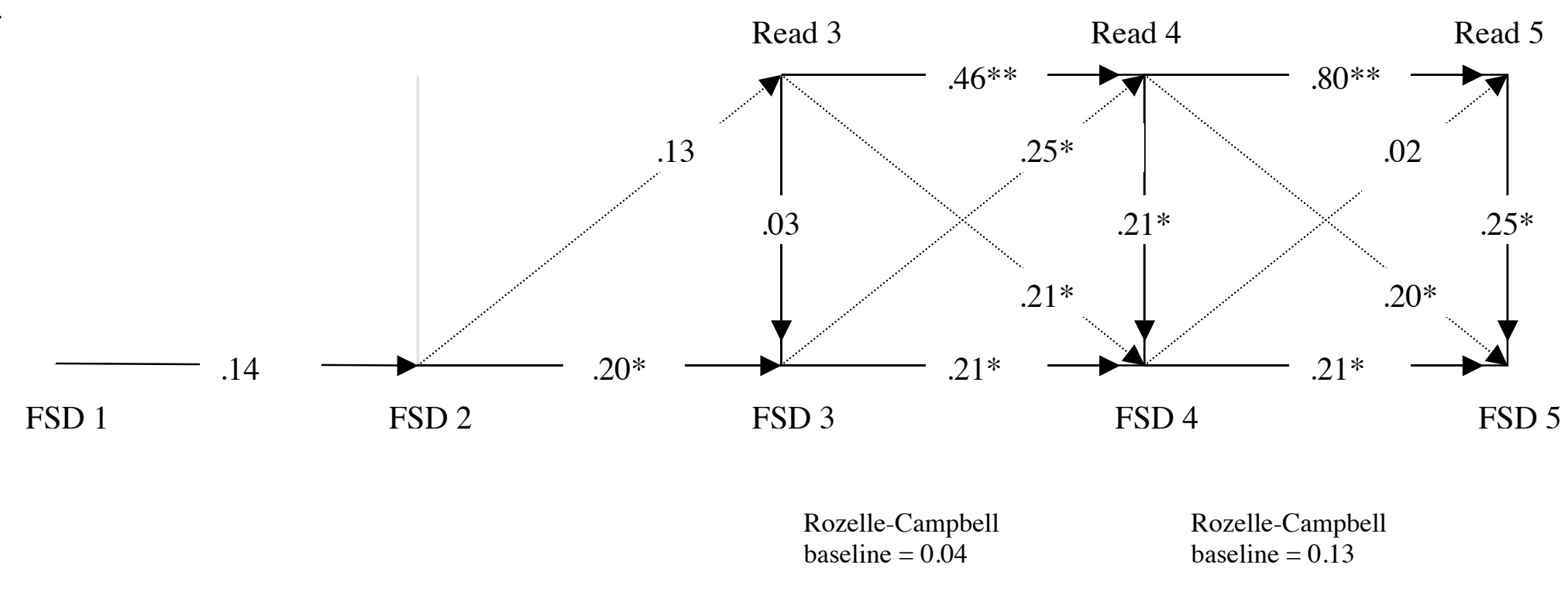

Figure 2. 


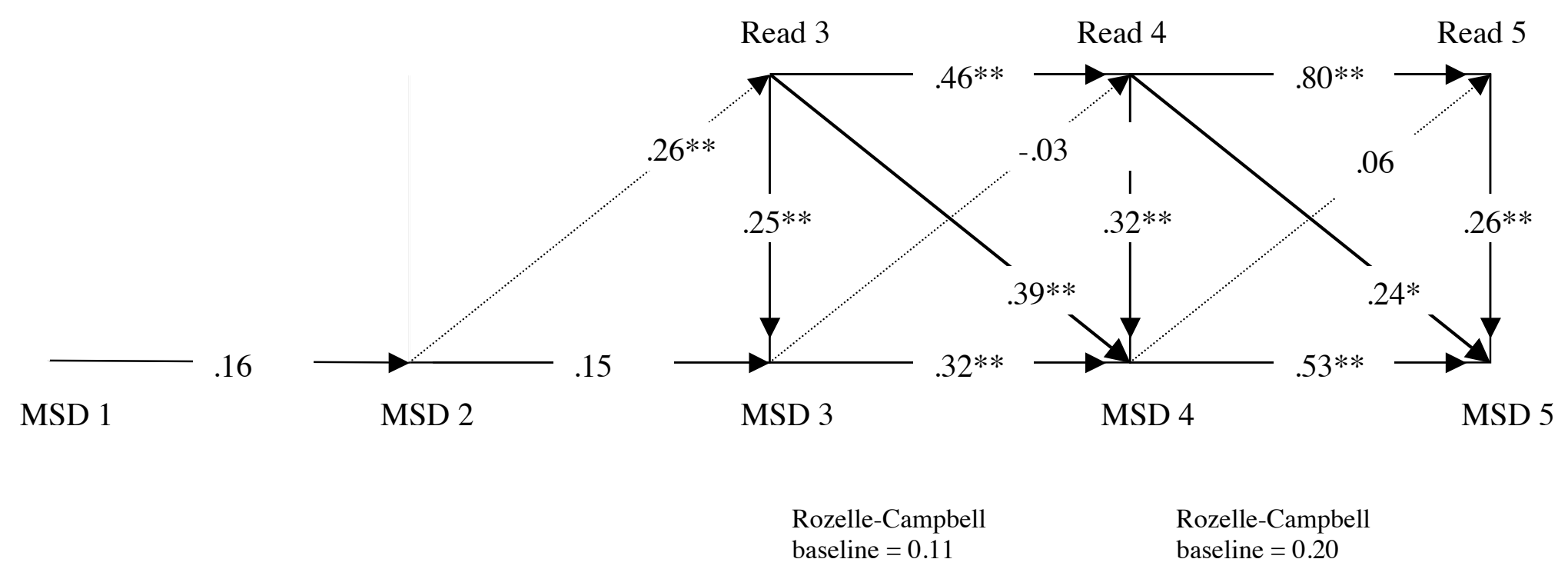

Figure 3. 


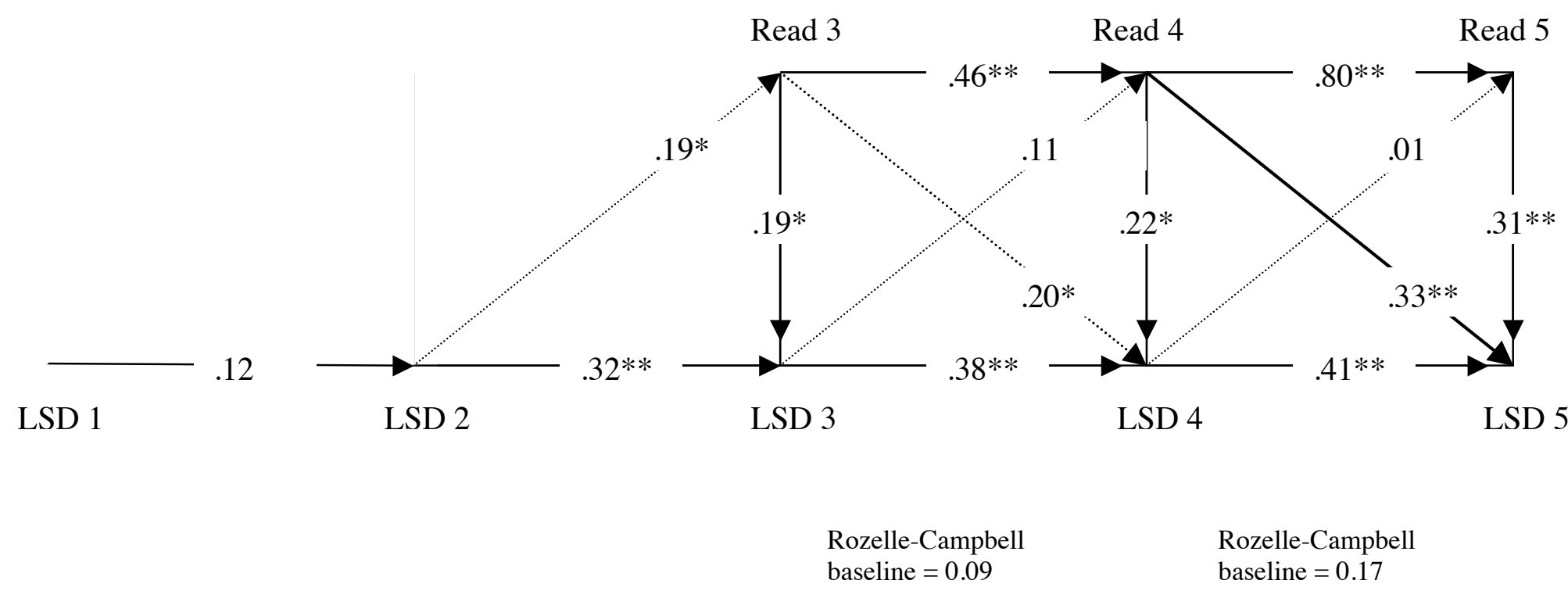

Figure 4. 


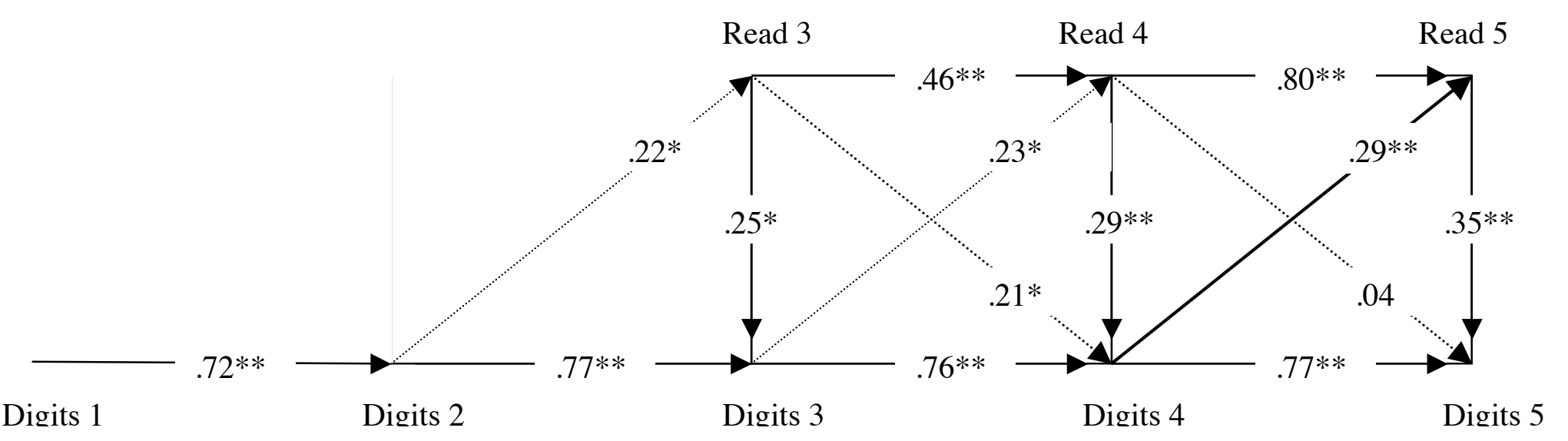

Rozelle-Campbell

baseline $=0.17$
Rozelle-Campbell

baseline $=0.25$

Figure 5. 


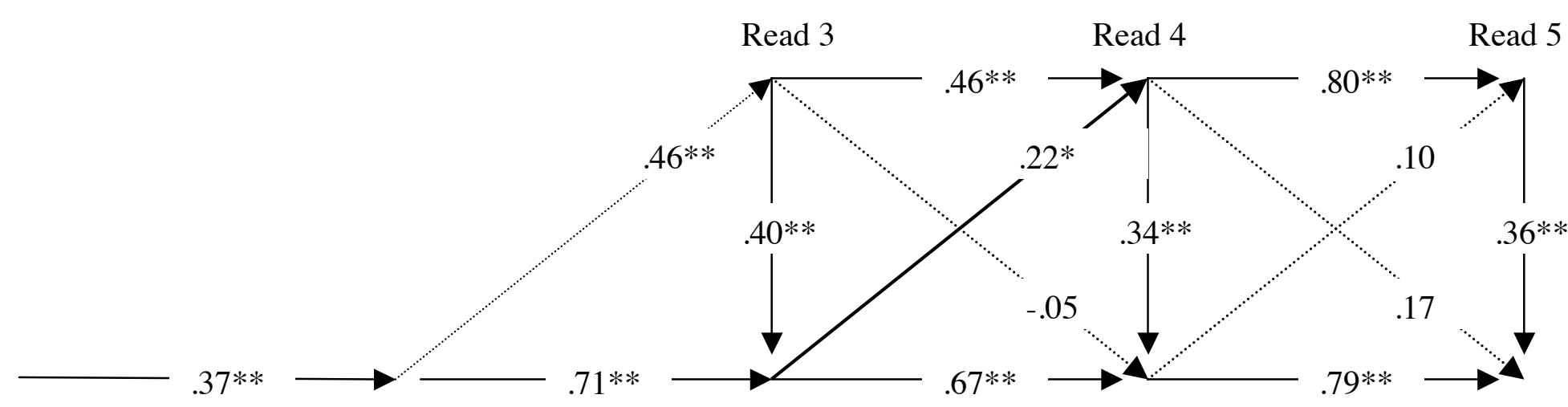

Blocks 1

Blocks 2

Blocks 3

Blocks 4

Blocks 5

Rozelle-Campbel

baseline $=0.21$

Rozelle-Campbell

baseline $=0.28$

Figure 6. 


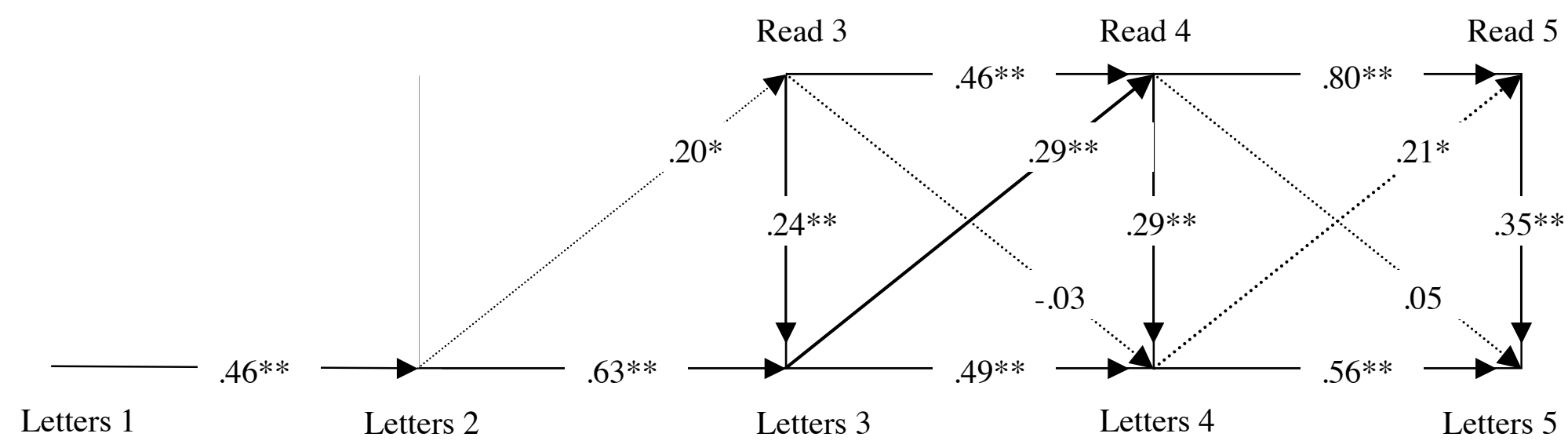

Rozelle-Campbell

baseline $=0.13$
Rozelle-Campbell

baseline $=0.22$

Figure 7. 


\section{Table 1}

Mean Scores (with Standard Errors) on the Tests at Each Stage

\begin{tabular}{lcccc}
\hline \multicolumn{1}{c}{ Variable: } & Stage 1 & Stage 2 & Stage 3 & Stage 4 \\
& Kindergarten & Year 1 & Year 2 \\
\hline $\mathrm{N}=$ & 142 & 142 & 108 & 107 \\
Mean age (months) & 45.4 & 50.6 & 57.5 & 62.8 \\
\hline
\end{tabular}

Phonological oddity task:

First sound different $($ maximum $=8)$

Middle sound different (maximum $=8$ )

Last sound different $($ maximum $=8$ )

Total $($ maximum $=24)$

Digit span $($ maximum $=34)$

Block design (maximum $=16$ )

Matching letter-like forms (maximum $=15)$

Single word reading $($ maximum $=18)$

Mean reading age (years)*

$\begin{array}{cccccc}1.85(0.12) & 2.36(0.09) & 2.21(0.09) & 2.59(0.12) & 3.38(0.17) & <0.01 \\ 2.78(0.15) & 3.45(0.08) & 3.33(0.12) & 3.49(0.16) & 3.83(0.18) & <0.01 \\ 2.32(0.13) & 3.17(0.12) & 3.21(0.16) & 3.51(0.19) & 4.28(0.22) & <0.01 \\ 6.88(0.33) & 8.92(0.21) & 8.62(0.26) & 9.46(0.37) & 11.38(0.46) & <0.01 \\ 10.92(0.30) & 11.56(0.29) & 13.06(0.35) & 14.83(0.38) & 14.99(0.38) & <0.01 \\ 1.18(0.10) & 1.39(0.12) & 1.99(0.18) & 3.08(0.24) & 4.71(0.30) & <0.01 \\ 4.17(0.21) & 5.37(0.26) & 6.90(0.32) & 9.25(0.30) & 10.95(0.32) & <0.01 \\ - & - & 0.33(0.08) & 2.87(0.24) & 4.54(0.31) & <0.01 \\ <5: 00 & <5: 00 & 5: 22 & 5: 85 & 6: 04 & \end{array}$

- as determined by the British Ability Scales Word Reading test. Norms on this test begin at 5:00 years so children in Stages 1 and 2, who were unable to read any of the words, were given a reading age of below 5:00 years. 
Table 2

Correlations Between the Measures at Each Stage

\begin{tabular}{|c|c|c|c|c|c|c|c|}
\hline & 1 & 2 & 3 & 4 & 5 & 6 & 7 \\
\hline \multicolumn{8}{|l|}{ Stage 1} \\
\hline 1. First sound different & - & $.573 * *$ & $.483 * *$ & $.207 *$ & .072 & .006 & - \\
\hline 2. Middle sound different & $.578 * *$ & - & $.577 * *$ & .123 & $.165 *$ & .068 & - \\
\hline 3. Last sound different & $.497 * *$ & $.582 * *$ & - & $.165 *$ & .100 & .121 & - \\
\hline 4. Digit span & $.223 * *$ & .134 & $.186^{*}$ & - & $.199 *$ & $.262 * *$ & - \\
\hline 5. Block design & .100 & $.181 *$ & .135 & $.222 * *$ & - & $.447 * *$ & - \\
\hline 6. Letter-like forms & .026 & .080 & .144 & $.276^{* *}$ & $.462 * *$ & - & - \\
\hline 7. Reading & - & - & - & - & - & - & - \\
\hline \multicolumn{8}{|l|}{ Stage 2} \\
\hline 1. First sound different & - & .130 & .094 & .205 & .159 & .030 & - \\
\hline 2. Middle sound different & .063 & - & $.410 * *$ & .114 & .007 & .118 & - \\
\hline 3. Last sound different & .074 & $.403 * *$ & - & .128 & .176 & .002 & - \\
\hline 4. Digit span & .086 & $.180 * *$ & .136 & - & $.324 * *$ & .074 & - \\
\hline 5. Block design & $.216^{* *}$ & .124 & .165 & .107 & - & $.351 * *$ & - \\
\hline 6. Letter-like forms & .044 & .133 & .044 & .159 & $.298 * *$ & - & - \\
\hline 7. Reading & - & - & - & - & - & - & - \\
\hline \multicolumn{8}{|l|}{ Stage 3} \\
\hline 1. First sound different & - & .111 & .163 & .154 & .077 & .099 & .069 \\
\hline 2. Middle sound different & .130 & - & $.287 * *$ & .084 & $.243 *$ & $.266 * *$ & $.263 * *$ \\
\hline 3. Last sound different & .182 & $.293 * *$ & - & $.300 * *$ & .087 & .073 & $.201 *$ \\
\hline 4. Digit span & .175 & .098 & $.316^{* *}$ & - & $.355^{* *}$ & $.318 * *$ & $.251 * *$ \\
\hline 5. Block design & .140 & $.267 * *$ & .112 & $.371 * *$ & - & $.519 * *$ & $.410^{* *}$ \\
\hline 6. Letter-like forms & .165 & $.288 * *$ & .103 & $.339 * *$ & $.600 * *$ & - & $.250 * *$ \\
\hline 7. Reading & .098 & $.275^{* *}$ & .188 & $.259^{*}$ & $.447 * *$ & $.306^{* *}$ & - \\
\hline \multicolumn{8}{|l|}{ Stage 4} \\
\hline 1. First sound different & - & $.367 * *$ & $.267 * *$ & $.243^{*}$ & $.327 * *$ & .102 & $.236^{*}$ \\
\hline 2. Middle sound different & $.413 * *$ & - & $.534 * *$ & $.367 * *$ & $.407 * *$ & .180 & $.355 * *$ \\
\hline 3. Last sound different & $.324 * *$ & $.570 * *$ & - & $.388 * *$ & $.261 * *$ & .158 & .146 \\
\hline 4. Digit span & $.238^{*}$ & $.358 * *$ & $.379 * *$ & - & $.328 * *$ & $.340 * *$ & $.391 * *$ \\
\hline 5. Block design & $.372 * *$ & $.463 * *$ & $.326 * *$ & $.312 * *$ & - & $.401 * *$ & $.242 *$ \\
\hline 6. Letter-like forms & .171 & $.248 * *$ & $.226^{*}$ & $.331 * *$ & $.461 * *$ & - & $.238^{*}$ \\
\hline 7. Reading & $.295^{* *}$ & $.419 * *$ & $.227 *$ & $.369 * *$ & $.355^{* *}$ & $.321 * *$ & - \\
\hline \multicolumn{8}{|l|}{ Stage 5} \\
\hline 1. First sound different & - & $.418 * *$ & $.398 * *$ & $.287 * *$ & $.335 * *$ & $.244 *$ & $.316^{* *}$ \\
\hline 2. Middle sound different & $.417 * *$ & - & $.562 * *$ & $.277 * *$ & $.333 * *$ & $.280 * *$ & $.302 *$ \\
\hline 3. Last sound different & $.423 * *$ & $.588 * *$ & - & $.446 * *$ & $.354 * *$ & $.375 * *$ & $.478 * *$ \\
\hline 4. Digit span & .180 & $.265^{* *}$ & $.396^{* *}$ & - & .109 & $.218^{*}$ & $.382 * *$ \\
\hline 5. Block design & $.398 * *$ & $.380 * *$ & $.406 * *$ & .027 &.- & $.532 * *$ & $.344 * *$ \\
\hline 6. Letter-like forms & $.196^{*}$ & $.311 * *$ & $.374 * *$ & $.265 * *$ & $.456 * *$ & - & $.364 * *$ \\
\hline 7. Reading & $.341 * *$ & $.346^{* *}$ & $.510 * *$ & $.341 * *$ & $.409 * *$ & $.358 * *$ & - \\
\hline
\end{tabular}

Note. Bivariate correlations are presented below the diagonal, partial correlations controlling for age are above the diagonal. * $p<.05 * * p<.01$ 